\title{
O QUE O CIRURGIÃO-DENTISTA PRECISA SABER SOBRE A SÍNDROME GILLES DE TOURETTE: RELATO DE CASO
}

Daniele Neiva de Lima MENDES; Renata TASSI; Fernando Henrique WESTPHALEN; Therezinha PASTRE

Síndrome de Gilles de Tourette é um transtorno neurológico relacionado com alterações do metabolismo e neurotransmissão dopaminérgica, patologia de comprometimento psicossocial, que acarreta alterações significativas na vida dos seus portadores e respectivos familiares, associada a uma variedade de problemas comportamentais e emocionais, se manifesta no começo da vida, afetando mais homens do que mulheres, caracterizada por tiques vocais e motores que são classificados em simples e complexos. Os tiques orofaciais e comportamentos compulsivos presentes nesta síndrome podem causar lesões bucais destrutivas. Os sinais e sintomas mais comumente observados são movimentos mandibulares acentuados, bruxismo, laceração severa das mucosas bucais, hipossalivação, devido medicações freqüentemente usadas no tratamento, associada ao desenvolvimento de cáries dentais e doenças periodontais. O objetivo deste trabalho é apresentar, os diversos aspectos da síndrome, incluindo a sua definição, a etiologia, o quadro clínico, a epidemiologia, o diagnóstico o tratamento e abordagem odontológica, bem como, relato de caso do paciente, MAC, masculino, leucoderma 30 anos, portador da síndrome, que se apresentou para tratamento odontológico com lesões bucais e fortes tiques motores e vocais. 